\title{
NARRATIVAS SOBRE O PROCESSO DA VIDA E DA MORTE MARGINAL DURANTE A PANDEMIA POR COVID-19
}

\begin{abstract}
Marco Orsini
Médico, Pós-Doutor em Neurologia pela Universidade Federal do Rio de Janeiro Professor Titular da Universidade de Medicina de Vassouras e Adjunto da Universidade de Nova Iguaçu. orsinimarco@hotmail.com

José Teixeira de Seixas filho

Biólogo, Pós-Doutor em Bioquímica pela Universidade Federal de Viçosa Professor Titular e Membro Permanente do Programa de Pós-Graduação em Desenvolvimento Local do Centro Universitário Augusto Motta jseixas4@gmail.com

Renata Rodrigues Teixeira de Castro Médica, Pós-Doutora em Cardiologia pela Universidade de Harvard, Professora associada da faculdade de Medicina da Universidade Iguaçu castrorrt@gmail.com

Jacqueline Fernandes do Nascimento Graduanda da Escola de Medicina Universidade Iguaçu Jac.fn@hotmail.com

\section{RESUMO}

As pandemias são epidemias de larga escala que se espalham pelo mundo. Nas últimas semanas, a população e os governos de todo o mundo têm dedicado esforços para frear o rápido avanço da pandemia de COVID-19, que infectou pessoas em 169 países. Além de mortes, problemas econômicos e o colapso dos sistemas de saúde dos países afetados, o espalhamento da pandemia provocou pânico generalizado. No entanto, notavelmente pouca atenção tem sido dedicada aos fatores psicológicos que influenciam a propagação da infecção pandêmica e o sofrimento emocional associado e a ruptura social e as perdas associadas aos fatores de vulnerabilidade psicológica que contribuem para a disseminação de doenças e angústias. $O$ presente artigo objetivou analisar e refletir sobre o medo, a ansiedade e a falta do rito da finalização da vida, afetando psicologicamente quem perde seus entes queridos sem o direito a despedida, perpetuando o luto. Muitos não estão sendo aceitos socialmente, desencadeando sofrimentos secundários e colaterais, os denominados lutos marginais e necessitam de urgentes ações de políticas públicas de apoios psicológicos, pois, notadamente pouca atenção tem sido dedicada a este sofrimento.
\end{abstract}

Palavras-chave: Luto. Pandemia. Fatores psicológicos. Mortes. 


\title{
NARRATIVES ABOUT THE LIFE AND MARGINAL DEATH PROCESSDURING THE PANDEMIC BY COVID-19
}

\begin{abstract}
Pandemics are large-scale epidemics that spread across the world. In recent weeks, people and governments around the world have devoted efforts to halt the rapid advance of the COVID-19 pandemic, which has infected people in 169 countries. In addition to deaths, economic problems and the collapse of health systems in the affected countries, the spread of the pandemic caused widespread panic. However, notably little attention has been paid to the psychological factors that influence the spread of pandemic infection and the associated emotional distress and social disruption and losses associated with the psychological vulnerability factors that contribute to the spread of illness and distress. This article aimed to analyze and reflect on fear, anxiety and the lack of the rite of ending life, psychologically affecting those who lose their loved ones without the right to parting, perpetuating the mourning. Many are not being accepted socially, triggering secondary and collateral suffering, the so-called marginal mourning and need urgent actions of public psychological support policies because, remarkably little attention has been devoted to this suffering.
\end{abstract}

Keywords: Mourning. Pandemic. Psychological factors. Deaths. 


\section{INTRODUÇÃO}

No Brasil a Pandemia da COVID-19 ainda demora a convencer a todos, mas principalmente ao poder público, de que sua gravidade não irá afetar a população da mesma maneira. Após esse período a população mundial terá outro comportamento, devido a um aprendizado que igualará classes sociais pelo sofrimento psicológico, fisiológico e econômico. No Brasil, esta situação afetará principalmente o comportamento dos que vivem em territórios vulneráveis, onde nos tempos de normalidade a governança não os alcançava, agora no pandêmico esta invisibilidade é midiaticamente divulgada, conforme mencionado por Dias (2020) quando ressaltou a falta de políticas públicas de proteção social para os indígenas, os encarcerados, os refugiados, os moradores de rua, entre outras populações que não são alcançadas pela miopia da governança em relação às políticas públicas protetivas.

A recomendação internacional da Organização Mundial de Saúde (OMS) e do Ministério da Saúde (MS), especificamente para o território brasileiro, da realização do isolamento social, não alcançam milhares de brasileiros sem teto, que representam mais uma parcela da população observada nas calçadas, nos viadutos e em qualquer outro espaço que sirva de abrigo, mas ignorada pela governança que, segundo Alvarez (2020) estão entre os mais desprotegidos da COVID-19.

A situação da epidemia de SARS-CoV-2 no Brasil apresenta crescimento exponencial de casos e mortes e a cidade de São Paulo "possui uma população não domiciliada que passou de 15.905 em 2015 para 24.344 em 2019 registrando um aumento de 53\%, sendo 13\% composta por idosos, dados gerados pela prefeitura" (ALVAREZ, 2020). O Brasil não conta com dados oficiais para a população em situação de rua (NATALINO, 2016).

Segundo Dias (2020) as populações vulneráveis como as sem domicílio, vivendo nas ruas, necessitam de programas específicos de esclarecimentos e assistência social, ressaltando ainda que "(...) em função de políticas neoliberais e redução dos investimentos sociais, matará mais, se políticas de proteção social e humanitárias, que respeitem a saúde, a vida e os direitos não forem implementadas emergencialmente".

A ocupação desordenada das cidades, formando territórios vulneráveis constituídos de moradores que vivem em condições degradantes em meio ao lixo, a falta de rede de esgoto, presença de animais sinantrópicos, devido a moradias inadequadas e improvisadas abrigando 
um núcleo familiar numeroso e convivendo com um ambiente de alta taxa populacional, que entra em contato direto com água contaminada, são determinantes de boa parte de mazelas que enfrentam populações de pobreza extrema. Esta é a realidade da maioria das comunidades periféricas das cidades brasileiras, onde a falta de água é recorrente.

A participação social é a forma local que encontraram para enfrentar uma pandemia desta grandeza, sem o amparo de um programa assistencial oficial de orientação e aporte estrutural e financeiro satisfatórios para que cumpram as principais recomendações de prevenção para conter a COVID-19.

Neste contexto, Lima (2020) comentou sobre a fragilidade destas comunidades em garantirem a prevenção e o isolamento social, pois são populações invisíveis, com geração de renda informal e que estão sendo os mais afetados, além da contaminação, pelos efeitos econômicos da pandemia.

As pandemias são epidemias de larga escala que se espalham pelo mundo. Os virologistas preveem que a próxima pandemia pode ocorrer nos próximos anos, provavelmente de alguma forma de influenza, com consequências potencialmente devastadoras. As vacinas, se disponíveis, e os métodos comportamentais são vitais para conter a disseminação da infecção. No entanto, notavelmente pouca atenção tem sido dedicada aos fatores psicológicos que influenciam a propagação da infeç̧ão pandêmica e o sofrimento emocional associado e a ruptura social.

Fatores psicológicos são importantes por várias razões. Eles desempenham um papel na não adesão aos programas de vacinação e higiene e desempenham um papel importante na maneira como as pessoas lidam com a ameaça de infecção e as perdas associadas. Os fatores psicológicos são ainda importantes para a compreensão e o gerenciamento dos problemas sociais associados às pandemias, como a disseminação do medo excessivo, estigmatização e xenofobia que ocorrem quando as pessoas são ameaçadas por infecção (TAYLOR, 2019).

Em relação ao sofrimento emocional associado às pandemias, pode-se inferir que se relaciona com a principal fonte de angústia das pessoas, pois ocorre um movimento sinérgico no sentido de se pensar no obstáculo da trajetória traçada quando do planejamento da vida. Este sentimento causa profunda perturbação, uma vez que cotidianamente não se pensa no corpo e sim o utiliza para alcançar os objetivos. No caso das doenças infecciosas, este pensar 
ainda é mais assustador, devido ao conhecimento de ter sido contaminado por outra pessoa. Isso pode transformar o medo da doença em medo do outro.

Neste sentido, Oliveira (2020) comentou sobre a ansiedade da população em distanciamento social, seja pela preocupação com a saúde ou por dificuldades econômicas reais, recomendando reduzir a procura de notícias constantes sobre a COVID-19, principalmente àquela com comorbidades, por possuir a sensação de população de risco iminente em caso de contaminação, podendo ocasionar o pânico.

O maior impacto da COVID-19 sobre a humanidade, ultrapassando os fatores de sofrimento psicológico para entendê-la e controla-la, é o de não poder realizar o ritual fúnebre de quem se ama. É uma reivindicação legítima e possui reação similar em todos os povos do planeta diante da perda por morte de um ente querido. Disser adeus pela última vez significa muito. O SARS-CoV-2 "está roubando [da população] a chance de se despedirem de seus entes queridos [...] tirando a dignidade dos mortos e agravando a tristeza dos vivos" (BETTIZA, 2020).

O presente artigo objetivou analisar e refletir sobre o medo, a ansiedade e a falta do rito da finalização da vida, desrespeitando diferentes crenças, afeta psicologicamente quem perde seus entes queridos sem o direito a despedida, perpetuando o luto.

\section{O SOFRIMENTO PSICOLÓGICO DO LUTO MARGINAL NA PANDEMIA}

A disseminação de doenças por organismos invisíveis de forma interpessoal ou mesmo ocasionar perigo por sobreviver numa camisa ou num lençol e infeccionar a próxima pessoa e, ainda, sem toque algum, propagando-se pelo ar, é fonte de grande sofrimento físico e psicológico, pois é de difícil mensuração das variáveis da situação de letalidade que se encontra. Neste sentido, Charleaux (2020) afirmou que esta situação "traz consigo medo e ansiedade em doses difíceis de serem administradas, ainda mais por pessoas que passaram a viver confinadas, sozinhas ou em família".

Bettiza (2020) chamou a atenção sobre um aspecto sanitário invisível que não está sendo contabilizado nesta pandemia por COVID-19 que é a saúde mental da população submetida à situação nunca antes experimentada.

Em relação às perdas de vidas para a COVID-19, de forma rápida e sem protocolos oficiais de amparo para quem fica, afirmou Färber (2013, p. 4) que o "desamparo é a 
cristalização do estado vivencial daqueles que tem seus lutos marginalizados, e que, a sociedade da qual faz parte, não tenha autorizado e aceito o seu luto".

Ferrari e Cunha (2020) relataram que ainda existem os que defendem a paralização do isolamento social, com argumentos que consideram a pandemia por SARS-CoV-2, proporcionalmente, com os índices de mortalidade "inferiores àquelas mortes derivadas de outras enfermidades ou processos sociais, como assassinatos e acidentes de trânsito" (FERRARI; CUNHA, 2020). Contudo, Färber (2013, p. 3) afirmou que "há lutos que não são aceitos socialmente, cuja elaboração é complexa e desencadeia sofrimentos secundários e colaterais, sendo denominados de lutos desautorizados e de lutos marginais".

A proibição do ritual fúnebre acarreta um sentimento semelhante aos que perdem seus entes queridos com ausência de cadáver, por diferentes sinistros, promovendo um luto problemático, levando a um maior tempo de sofrimento para quem fica (ARAÚJO, 2009).

Devido à alta Taxa de Mortalidade por COVID-19, iniciada no Brasil pelo estado de São Paulo, as cerimônias fúnebres foram proibidas, como protocolo sanitário para evitar a transmissão do SARS-CoV-2 (SILVA, 2020), sendo este protocolo seguido por todos os estados brasileiros, conforme recomendação da OMS e do Ministério da Saúde.

A COVID-19 impacta a vida da humanidade de forma profunda, principalmente àquelas pessoas que perderam familiares, assim como as que sofrem de ansiedade. Contudo, existem os que amenizam esta sintomatologia de medo e apreensão extrema pela negação dos fatos, sendo uma atitude perigosa tanto para si quanto para os que o cercam. Neste sentido, Kovács (2008) afirmou ainda que por ser uma situação nova e ainda em desenvolvimento não foi criado protocolos de proteção psicológica, no entanto, afirmou que a comunicação é o caminho para situações de crise e de desorganização como instrumento de acolhimento, principalmente da área de saúde mental, incluindo o reconhecimento do luto, mesmo que de forma virtual.

Nesse sentido, destaca-se a importância do trabalho do psicólogo hospitalar ao atendimento dos usuários e de seus familiares, especialmente em casos de terminalidade e morte. De acordo com Kübler-Ross (1998 apud SCHMIDT; GABARRA; GONÇALVES, 2011, p. 423) "a família da pessoa enferma deve ser levada em consideração, haja vista que o papel dos familiares e suas reações, durante essas situações, influenciam e contribuem sobremaneira nas reações do próprio doente". 
Existe pouca abordagem na literatura médica sobre os cuidados aos familiares de pacientes em situação intra-hospitalar (SOARES, 2007). Contudo, de forma geral, sobre a saúde mental reconhece a imprescindibilidade da importância familiar no paciente terminal, finalizando trajetórias e concluindo questões pendentes de diferentes ordens de sentimentos (KÜBLER-ROSS, 1998; BORGES et al., 2006). Esta metodologia vem apresentando resultados psicológicos positivos para os que perdem seus entes queridos (FINEBERG, 2005).

“Embora o psicólogo, como um profissional de saúde, lide frequentemente com questões relacionadas à morte em seu cotidiano de trabalho, a temática da terminalidade ainda é tratada de maneira incipiente [...]" pontuam Junqueira e Kovács (2008 apud SCHMIDT; GABARRA; GONÇALVES, 2011, p. 424).

\section{CONSIDERAÇÕES FINAIS}

Existem atores, que não cabe citá-los, que de forma catastrófica e desastrosa protagonizam e "agudizam" seu discurso natural e simplório sobre o adoecimento e a morte. Escutam-se diariamente relatos que na história da humanidade as pessoas não param de morrer; que a morte é um processo natural e anda em linha tênue com a palavra vida. Verbalizações sobre torturas físicas, sociais e raciais são comumente tratadas como questões históricas e comuns.

Pode-se inferir pelo que se observa no comportamento de parte da sociedade, que existe uma banalização da morte como um processo de defesa psíquica, já se adiantando a um mal pior. Contudo, este posicionamento vem acarretando extrema insensatez durante essa pandemia. Não se podem encarar indivíduos como números e, ou, estatísticas. Em meio à COVID-19 vislumbra-se com terror a prova desta banalização, em mensagens difundidas por diferentes meios de comunicação, principalmente nas mídias sociais, podendo-se observar que as pessoas parecem não se escandalizarem com os óbitos contabilizados diariamente.

Uma epidemia não pode ser sinônimo de conformismo. O brasileiro passa a lidar com certa naturalidade e descompasso humano com a brutalidade de cenas, dos choques psíquicos e com as informações midiáticas. É notório e óbvio que os processos de nascer e morrer são naturais e inerentes a todos os seres-humanos; mas não é essa a crítica que se faz. Esse "trato" com o processo de morte durante a pandemia por COVID-19 parece estar incorporando-se no 
tecido social, chegando mesmo a se tornar uma epidemia nacional. Do dia para a noite famílias carreiam seus parentes aos hospitais e dias depois possuem alguns minutos, quando lhes é ofertado, para uma diminuta prece ou homenagem. Não há indignação com as questões várias que envolvem esse processo; nos preocupa o que realmente cada brasileiro carreia do lado esquerdo do seu peito. Vê-se naqueles momentos de médicos, a "brutalidade" diante do profissional. Homens que não querem se separar de familiares sendo contido nas emergências dos hospitais. Tornamo-nos uma sub-raça? Hoje, infelizmente, a morte parece não ter a mínima importância.

Precisa-se sair adiante em busca de solidariedade. Existe alguma linha de raciocínio pleno relativo à limpeza social de população supérflua? Que população seria essa? Está sendo construído um senso comum do excesso populacional, economicamente supérflua e socialmente sem raízes? O povo realmente mudou ou sempre banalizou tais fatos?

A organização da sociedade é fundamental para ampliar a conscientização por meio da comunicação e do acolhimento esclarecedor, com fomentos e Ciência, que deverá preservar o sistema de saúde dando condições de se ampliar a sua estrutura combalida e deficiente, por décadas de descaso e impunidade da má gestão pública, viabilizando cumprir satisfatoriamente a demanda que ainda estará por vir, ampliando o espaço de tempo para a contaminação da população, por meio do isolamento social.

Torna-se urgente o planejamento de protocolos na área da medicina mental para suturar as feridas deixadas pela COVID-19 que se prolongarão pela não aceitação do luto, que gerarão sofrimentos secundários e colaterais numa grande parcela da população, principalmente as das comunidades vulneráveis e das populações invisíveis do Brasil, que possuem historicamente morbidades sociais.

É igualmente urgente a organização, por parte do governo brasileiro, para programar medidas emergenciais eficazes, de forma diferenciada, de acordo com as necessidades das camadas sociais do Brasil, aqui já discutidas, correlacionando sinergicamente o tempo, a ética e o acolhimento, material e psicológico, visando fortalecer o povo brasileiro que vivência o caos das incertezas, que geram ansiedade e pânico, em todos os tempos e para todas as idades.

Dentre tantos desafios a serem enfrentados o mais importante é a manutenção da vida. A morte provocada por um inimigo invisível em pleno século XXI nos remete aos pesadelos dos Séculos XVI, XVII, XVII e XIX, quando se vivenciou da Varíola à AIDS. A esperança é a 
velocidade atual dos achados científicos, estes precisam ser plenamente e mundialmente apoiados, pois a morte é a mais desafiadora das realidades que o ser humano tem que enfrentar, mais do que a morte filosófica, ao longo da existência, que derrubam paradigmas; ou mesmo a psicológica, por meio das mortes simbólicas. A morte biológica é definitiva e sempre haverá quem a ache cruel, principalmente, para os que amam. Por isso da necessidade de se concretizar a despedida, o último gesto que acalma a mente de quem fica.

Até mesmo as mortes simbólicas são carregadas de expressões do fim que marca a morte efetiva e real, por isso, há que se promoverem meios para facilitar o enfrentamento desses acontecimentos.

\section{REFERÊNCIAS}

ALVARES, I. População de desabrigados está entre as mais vulneráveis a COVID 19. Diário de Pernambuco, 6 abr. 2020. Notícia de Brasil. Cenário. Disponível em: https://www.diariodepernambuco.com.br/noticia/brasil/2020/04/populacao-de-desabrigadosesta-entre-as-mais-vulneraveis-a-covid-19.html. Acesso em: 11 maio 2020.

ARAÚJO, F. A. Morte sem corpo e sem sepultura: notas sobre desaparecimento forçado hoje. In: Reunión de Antropología del Mercosur, 8., 2009, Buenos Aires. Anais [...]. Buenos Aires: [S. n.], 2009.

BETTIZA, S. Coronavírus: a dor das famílias proibidas de enterrar seus mortos na Itália. BBC News Brasil, 25 mar. 2020. BBC World Service. Disponível em: https://www.bbc.com/portuguese/geral-52025235. Acesso em: 10 maio 2020.

BORGES, A. D. V. S. et al. Percepção da morte pelo paciente oncológico ao longo do desenvolvimento. Psicologia em Estudo, Maringá, v. 11, n. 2, p. 361-369, maio/ago. 2006. Disponível em: https://www.scielo.br/scielo.php?pid=S141373722006000200015\&script=sci_arttext. Acesso em: 26 maio 2020.

CHARLEAUX, J. P. Luto, medo e ansiedade: o sofrimento psicológico na pandemia. Nexo, 13 abr. 2020. Entrevista. Documento atualizado em 15 maio 2020. Disponível em: https://www.nexojornal.com.br/entrevista/2020/04/13/Luto-medo-e-ansiedade-o-sofrimentopsicol\%C3\%B3gico-na-pandemia. Acesso em: 10 maio 2020.

DIAS, Bruno C. Pandemia do COVID 19 e um Brasil de desigualdades: populações vulneráveis e o risco de um genocídio relacionado a idade. [S. I.]: ABRASCO, 2020. Assinam este documento: Alexandre Kalache (ILC Brasil), Alexandre Silva (Faculdade de Medicina de Jundiaí e ILC Brasil), Luiz Ramos (UNIFESP), Marilia Louvison (Faculdade de Saúde Pública da USP e ILC Brasil), Renato Veras (UNATI /UERJ e RBGG), Kenio Lima (UFRN e RBGG). Disponível em: 
https://www.abrasco.org.br/site/gtenvelhecimentoesaudecoletiva/2020/03/31/. Acesso em: 11 maio 2020.

FÄRBER, S. S. Lutos marginais e lutos desautorizados, ritos negados e omitidos. Protestantismo em Revista, São Leopoldo, v. 32, p. 3-14, set./dez. 2013. Disponível em: http://periodicos.est.edu.br/index.php/nepp/article/view/1119/1058. Acesso em: 26 maio 2020.

FERRARI, A.; CUNHA, A. M. A pandemia de Covid-19 e o isolamento social: saúde versus economia. Porto Alegre: UFRGS, 2020. Criado em 28 mar. 2020, atualizado em 30 mar. 2020. Disponível em: https://www.ufrgs.br/coronavirus/base/artigo-a-pandemia-de-covid-19-e-oisolamento-social-saude-versus-economia/. Acesso em: 09 maio 2020.

FINEBERG, I. C. Preparing professionals for family conferences in palliative care: evaluation results of an interdisciplinary approach. Journal of Palliative Medicine, v.8, n. 4, p. 857-866, Aug. 2005.

KOVÁCS, M. J. Desenvolvimento da Tanatologia: estudos sobre a morte e o morrer. Ribeirão Preto. Paidéia, Ribeirão Preto, v. 18, n. 41, p. 457-468, set./dez. 2008. Disponível em: https://www.scielo.br/pdf/paideia/v18n41/v18n41a04.pdf. Acesso em: 26 maio 2020.

KÜBLER-ROSS, E. Sobre a morte e o morrer. P. Menezes, Trad. São Paulo: Martins Fontes. 1998.

LIMA, J. D. Por que as periferias são mais vulneráveis ao coronavírus. Nexo, 18 mar. 2020. Disponível em: https://www.nexojornal.com.br/expresso/2020/03/18/Por-que-as-periferiass\%C3\%A3o-mais-vulner\%C3\%A1veis-ao-coronav\%C3\%ADrus. Acesso em: 08 maio 2020.

NATALINO, M. A. C. Estimativa da população em situação de rua no Brasil. Brasília: IPEA, 2016. Disponível em:

https://www.ipea.gov.br/portal/index.php?option=com_content\&view=article\&id=28819. Acesso em: 11 maio 2020.

OLIVEIRA R. A história nos ensinou que as pessoas são resilientes. Pública, 24 mar. 2020. Disponível em: https://apublica.org/2020/03/a-historia-nos-ensinou-que-as-pessoas-sao-resilientesdiz-autor-do-livro-a-psicologia-da-pandemia/. Acesso em: 11 maio 2020.

SCHMIDT, B.; GABARRA, L. M.; GONÇALVES, J. R. Intervenção psicológica em terminalidade e morte: relato de experiência. Paidéia, Ribeirão Preto, v. 21, n. 50, p. 423-430, set./dez. 2011. Disponível em: https://www.scielo.br/pdf/paideia/v21n50/15.pdf. Acesso em: 27 maio 2020.

SILVA, W. A dor da falta de despedida em tempos de isolamento social. Folha de Pernambuco, 11 abr. 2020. Notícias. Coronavírus. Disponível em:

https://www.folhape.com.br/noticias/noticias/coronavirus/2020/04/11/NWS,136817,70,1668,NOTICIAS ,2190-A-DOR-FALTA-DESPEDIDA-TEMPOS-ISOLAMENTO-SOCIAL.aspx. Acesso em: 09 maio 2020. 
SOARES, M. Cuidando da família de pacientes em situação de terminalidade internados na unidade de terapia intensiva. Rio de Janeiro, Revista Brasileira de Terapia Intensiva, v. 19, n. 4, p. 481-484, out./dez. 2007.

TAYLOR, S. The psychology of pandemics preparing for the next global outbreak of infectious disease. London: Cambridge Scholars Publishing, 2019. 175 p.

Recebido em 12/05/2020

Aceito em 19/05/2020 